\title{
Updates in Prostate Cancer Research and Screening in Men at Genetically Higher Risk
}

\author{
Elizabeth K. Bancroft ${ }^{1,2}$ (D) Holly Ni Raghallaigh ${ }^{1,2} \cdot$ Elizabeth C. Page $^{1,2} \cdot$ Rosalind A. Eeles $^{1,2}$
}

Accepted: 12 July 2021 / Published online: 8 October 2021

(c) The Author(s) 2021

\begin{abstract}
Purpose of Review Prostate cancer (PrCa) is the most common cancer in men in the western world and is a major source of morbidity and mortality. Currently, general population PrCa screening is not recommended due to the limitations of the prostate-specific antigen (PSA) test. As such, there is increasing interest in identifying and screening higher-risk groups. The only established risk factors for PrCa are age, ethnicity, and having a family history of PrCa. A significant proportion of PrCa cases are caused by genetic factors.

Recent Findings Several rare germline variants have been identified that moderately increase risk of PrCa, and targeting screening to these men is proving useful at detecting clinically significant disease. The use of a "polygenic risk score" (PRS) that can calculate a man's personalized risk based on a number of lower-risk, but common genetic variants is the subject of ongoing research. Research efforts are currently focusing on the utility of screening in specific at-risk populations based on ethnicity, such as men of Black Afro-Caribbean descent. Whilst most screening studies have focused on use of PSA testing, the incorporation of additional molecular and genomic biomarkers alongside increasingly sophisticated imaging modalities is being designed to further refine and individualise both the screening and diagnostic pathway. Approximately $10 \%$ of men with advanced PrCa have a germline genetic predisposition leading to the opportunity for novel, targeted precision treatments. Summary The mainstreaming of genomics into the PrCa screening, diagnostic and treatment pathway will soon become standard practice and this review summarises current knowledge on genetic predisposition to PrCa and screening studies that are using genomics within their algorithms to target screening to higher-risk groups of men. Finally, we evaluate the importance of germline genetics beyond screening and diagnostics, and its role in the identification of lethal $\operatorname{PrCa}$ and in the selection of targeted treatments for advanced disease.
\end{abstract}

Keywords Prostate cancer · Prostate cancer screening · Family history $\cdot$ Genetic predisposition $\cdot$ Genetic variants . Polygenic risk score

\section{Introduction}

Prostate cancer $(\mathrm{PrCa})$ remains one of the major causes of morbidity and mortality among men worldwide with over 1.4 million new cases and 375,000 deaths recorded in 2020

This article is part of the Topical collection on Cancer Genomics

Elizabeth K. Bancroft

elizabeth.bancroft@rmh.nhs.uk

$\bowtie$ Elizabeth C. Page

1 Urology Genetics, The Royal Marsden NHS Foundation Trust, Downs Road, SM2 5PT Sutton, UK

2 Oncogenetics Team, The Institute of Cancer Research, 15 Cotswold Road, SM2 5NG Sutton, UK
[1-3]. Incidence of PrCa has been increasing in recent decades, and age, ethnicity and having a PrCa family history $(\mathrm{FH})$ are the only established risk factors [4].

The greatest challenge within PrCa screening is developing screening tests that are able to differentiate between indolent, slow-growing tumours and tumours that behave aggressively which require treatment. For men diagnosed with localised low-grade $\mathrm{PrCa}$, the 5-year survival rate is effectively $100 \%$; however, for those with metastatic disease at diagnosis, this reduces to only $30 \%$ [4]. The aim is therefore to optimise screening approaches in order to detect clinically significant cancers whilst the disease is treatable to reduce the burden of the disease on men's lives, whilst at the same time avoiding the harms of overdiagnosis and overtreatment of indolent, screen-detected disease. 


\section{Risk Factors - Age}

Incidence of PrCa rises steeply from age 50, with two-thirds of cases being diagnosed over the age of 70 years [2]. However, the incidence of $\mathrm{PrCa}$ in men under 55 years is increasing each year. It has been suggested that men with early-onset $\mathrm{PrCa}$ can have more aggressive disease and poorer survival than men diagnosed at an older age. These men are likely to be those who carry germline genetic variants that increase their susceptibility to developing $\operatorname{PrCa}$.

\section{Risk Factors - Ethnicity}

PrCa incidence and mortality rates vary across different ethnic groups, with the greatest risk and highest mortality rates seen in men of African ancestry and lowest seen in men of Asian ancestry [5]. In the USA, PrCa incidence in African American men is estimated to be approximately 1.76 -fold higher than those of European ancestry and PrCa mortality rates 2.20-fold higher in black men [6]. A large retrospective study in the USA found that whilst overall survival from PrCa is poorer in men of African ancestry compared with men of European ancestry, once they had adjusted for socioeconomic status and matching men by stage, there was no difference in survival. Therefore, this suggests that the majority of the poorer disease outcomes in black men were due to socioeconomic factors. Therefore, genetic variation may play some role, but socioeconomics are likely to play a greater role in Black men $[7,8]$.

\section{Risk Factors - Family History}

FH is one of the strongest risk factors, with risk increasing with the number of relatives affected and the younger their age at diagnosis [9]. Men with one first-degree relative have an estimated risk of 2.5 times the general population risk. Research in twins has provided evidence for a substantial heritable component in the development of $\mathrm{PrCa}$, estimated to be the most heritable of all common cancers, with 58\% heritability [10]. There is evidence for aggressive PrCa clustering within families, including monozygotic twins, suggesting a genetic basis for aggressive disease [11, 12]. It is suggested that familial prostate cancer may be more biologically aggressive than sporadic cancers, with men more likely to relapse and have poorer outcomes after radical prostatectomy [13]. PrCa has also been demonstrated to cluster in families with a strong FH of other cancers, in particular breast cancer $[14,15]$.

\section{Risk Factors - Genetic Predisposition}

There is strong evidence for genetic predisposition to $\mathrm{PrCa}$ $[16,17,18]$. There are rare (found in $<1 \%$ of men) susceptibility variants, inherited dominantly and that moderately increase the risk of $\mathrm{PrCa}$ and common genetic variants (present in $>5 \%$ of men) which individually confer a small increased risk of PrCa. Each of these common variants do not individually increase risk to a clinically significant level, but they are thought to act multiplicatively to increase risk to potentially clinically significant levels. Our current knowledge on both rare and common PrCa risk variants is summarised and shown in Fig. 1.

\section{Prostate Cancer - Genetic Variants}

\section{Dominantly Inherited, Higher Risk Genetic Variants}

There is strong evidence that pathogenic variants in DNA repair genes increase the risk of $\mathrm{PrCa}$ and predispose to aggressive disease and poorer clinical outcomes [16, 17, $18,19,20,21,22,23,24,25,26,27]$. An estimated 8-12\% of men with metastatic PrCa have germline mutations in tumour suppressor genes [27, 28, 29]. Men carrying pathogenic variants in the $B R C A 2$ gene aged $<65$ years old have an estimated relative risk of $\mathrm{PrCa}$ of 2.5-8.6-fold [30, 31, $32]$ and a significantly increased risk of early-onset, aggressive disease [20, 21, 22, 26, 33, 34, 35, 36]. Other DNA repair genes have been implicated as conferring a moderate$\mathrm{PrCa}$ risk in studies of men with young onset or metastatic $\mathrm{PrCa}$ and require further investigation in larger prospective cohorts. These include BRCAI (estimated 1.8-3.5-fold increased risk) [37, 38], ATM (odds ratio of 4.4) [20, 39], CHEK2 (odds ratio of 1.8-8.2) [40,41], PALB2 (odds ratio of 3.5) [40, 42] and HOXB13 G84E variant (odds ratio of 0.95-93) [40, 43, 44, 45]. The ranges of these risk estimates are wide as pathogenic variants in these genes are rare, and the data have been ascertained from different cohorts of men; for example, case-control studies selected for family history, or unselected cases with aggressive disease. For CHEK2, most of the data relate to the $1100 \mathrm{delC}$ variant, but other pathogenic variants in $C H E K 2$ have also been implicated in increasing risk of aggressive disease. For HOXB13, risk estimates relate to the missense mutation G84E, which is a founder mutation in Nordic populations, with carrier frequencies reported to be $0.2-1.4 \%$ and $0.1-0.5 \%$ in other Western European populations.

The DNA mismatch repair genes MSH2, MSH6 and $M L H 1$ are reported to increase PrCa risk between 2- and tenfold [46, 47, 48, 49, 50] with a meta-analysis by Ryan et al. reporting a 2.13-fold increased risk of PrCa [50]. There is also evidence to suggest an association with higher-grade tumours and younger age of onset $[47,48,51]$ associated with pathogenic variants in $M S H 2$ compared to the other MMR genes [46, 48, 49, 52, 53, 54]. Other genes such as RAD51D, TP53, BRIP1 and NBN [27, 55, 56] have also been proposed as potentially involved in PrCa development. 


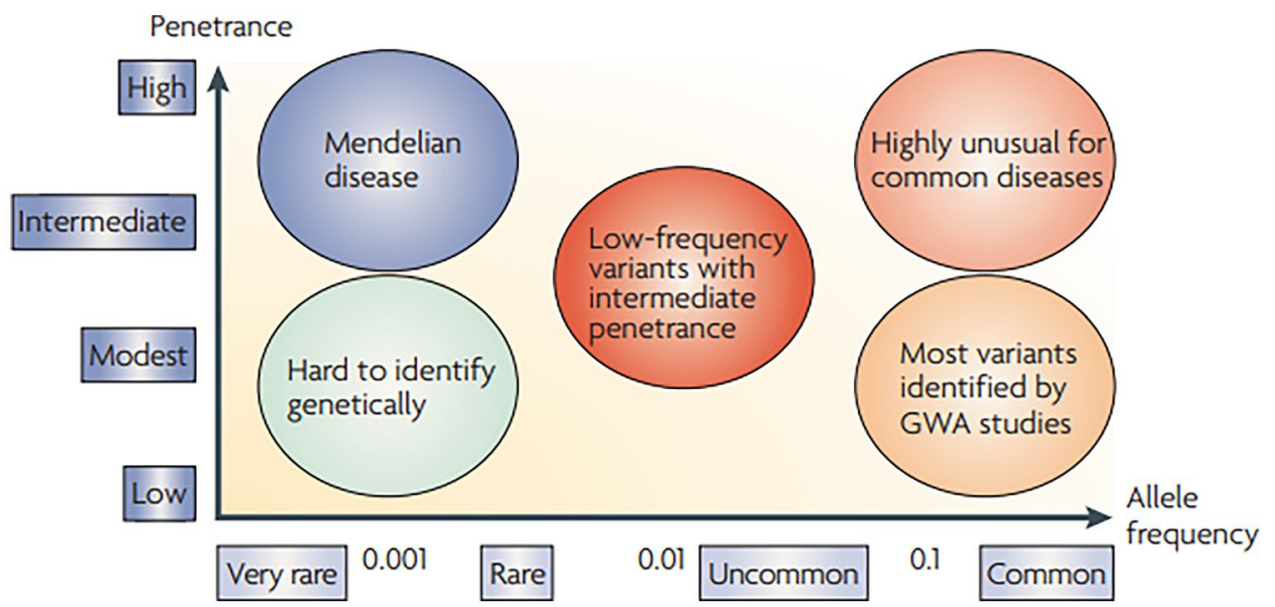

Fig. 1 Spectrum of genetic variation in diseases. The $\mathrm{X}$-axis represents the frequency of the variant allele in the general population, the Y-axis represents the penetrance of the variant. Highly penetrant variants responsible for Mendelian disease which occur very rarely in the general population (i.e. Li-Fraumeni Syndrome) fall in the top left of the diagram. Low-penetrance, but common variants such as those dis- covered for PrCa risk by large-scale GWAS studies are in the bottom right of the graph (red arrow). Reprinted by permission from Springer Nature: Nature Genetics Reviews [21]. Genome-wide association studies for complex traits: consensus, uncertainty and challenges. McCarthy et al. Copyright@2008

Ashkenazi Jewish ancestry [57]. The NCCN Prostate Cancer Early Detection [60] and Genetic/Familial High-Risk assessment [61] guidelines recommends referral to a genetics professional if there is a known, or suspected cancer susceptibility pathogenic gene variant. If an unaffected man has a personal history of male breast cancer or exocrine pancreatic cancer, Ashkenazi-Jewish ancestry, a probability of $>5 \%$ of carrying a $B R C A 2$ pathogenic variant based on a probability model, having a first or second-degree relative with any of the following: breast cancer aged $\leq 45$, breast cancer aged 46-50 with a second breast cancer diagnosed at any age, breast cancer aged $46-50$ with $\geq$ close blood relative with breast, pancreatic, ovarian or prostate cancer [61].

\section{Common Genetic Variants and Polygenic Risk Score}

Common genetic variants, or single nucleotide polymorphisms (SNPs), occur in $>5 \%$ of the population. Largescale genome-wide association studies (GWAS) have led to the discovery of over 200 SNPs associated with PrCa risk (reviewed in [9]). Each SNP has a low penetrance and confers a small increase in PrCa risk if occurring alone, but are thought to act multiplicatively. Over $30 \%$ of the familial risk in PrCa can be explained by the SNPs identified to date, with men in the top $1 \%$ of the risk profile having a 5.7 -fold increase in risk of developing PrCa compared with the average population risk [62]. Therefore, a number of men in the upper end of the risk distribution may have an elevated risk similar to that of men who carry mutations in moderate-risk genes [26]. These advances in our knowledge about common 
variants and their contribution to risk of $\mathrm{PrCa}$ are therefore ready for implementation in clinical studies evaluating their use in population risk-stratification [63]. A polygenic risk score (PRS) can be calculated from a man's PrCa risk-SNP genotype to estimate his individual risk of developing $\mathrm{PrCa}$ relative to the average population risk. This genotyping is a much cheaper option than the cost of the sequencing of gene panels, to screen for rare pathogenic mutations. There is also evidence to suggest that stratifying screening to men at the highest-risk of PrCa, based on their PRS, could potentially reduce overdiagnosis and improve the cost-effectiveness of a PrCa screening programme [64].

Currently, most GWAS data are from European populations, and so, the calculation of PRS in men of other ethnicities requires further consideration. Multi-ethnic GWAS have found that many (but not all) PrCa risk SNPs are shared between populations; however, the risk associated with a variant may vary according to ethnicity. Recently, Darst et al. reported the importance of a SNP specific to men of African ancestry and its role in increasing these men's risk of PrCa at an early age [42]. A recent multi-ethnic GWAS has identified 86 new SNPs associated with increased PrCa risk in men of African ancestry, and of interest, these are associated with higher-per-allele odds ratios than many of those in European men [65].

The modifying effect of SNPs in men with known pathogenic variants in cancer predisposition genes is an area of increasing interest. Lecarpentier et al. (2017) genotyped approx. 1800 men with known $B R C A 1$ or $B R C A 2$ variants for 103 known PrCa risk SNPs [66]. Large differences in absolute cancer risks were seen at the extremes of the PRS distribution in their BRCA cohort. For example, PrCa risk at age 80 at the 5th and 95th percentiles of the PRS varied from 7 to $26 \%$ for carriers of $B R C A 1$ mutations and from 19 to $61 \%$ for carriers of $B R C A 2$ mutations, highlighting that a PRS can further inform us of heritable risk in such men and help further risk stratify this already high-risk cohort.

\section{Genetic Predisposition to Prostate Cancer - Summary}

PrCa risk is influenced by a combination of common and rare germline variants, with rare variants important within specific families and sub-groups and common variants a substantial contributor at the population level [9]. Identifying an underlying genetic predisposition to $\mathrm{PrCa}$ is important for a number of reasons. For those identified at higher risk, tailored or targeted screening protocols can be implemented. For men receiving a diagnosis of locally advanced or metastatic disease, there are treatment implications relating to the use of targeted, molecular therapy if a germline variant is present. Finally, there is the critical opportunity for cascade testing amongst family members in those with moderate/ higher risk variants. Cascade testing is important as many of the moderate risk genes implicated in the development of PrCa are well-established to predispose to several cancers, for which screening and risk-reducing measures may be available. Pathogenic variants in genes such as BRCAl, $B R C A 2$ and MMR genes are well characterised with clear clinical management guidelines. There are also family planning options such as pre-implantation genetic diagnosis that can be explored.

\section{Prostate Cancer Screening}

The prostate-specific antigen (PSA) test is the most commonly utilised PrCa biomarker currently available but is not recommended as a general population screening tool due to its well-documented limitations [67, 68]. Data from large screening trials including the European Randomised Study of Screening for Prostate Cancer (ERSPC) [69, 70] and Prostate, Lung, Colorectal and Ovary screening study (PLCO) [71, 72] do not support population screening using PSA, despite evidence of a $21 \%$ reduction in PrCa-specific mortality after 13 years of follow-up, and evidence to support earlier diagnosis increasing the likelihood of cure [70]. The major limitation is the inability of PSA to discriminate between clinically significant cancer and indolent disease that will not affect a man during his lifetime. The harms of 'unnecessary' prostate biopsies resulting in overdiagnosis and over treatment of indolent cancers, together with the psychological burden of life-changing side effects of treatments such as incontinence and erectile dysfunction, are felt to outweigh any benefit in potential mortality reduction. It is not feasible to use expensive imaging techniques, for example MRI-fusion technologies, at a population level without limiting numbers by classifying men into different risk categories. Although there has been much focus on new molecular and genomic biomarkers for diagnosing $\mathrm{PrCa}$ [73], to date, prostate-specific antigen (PSA) remains the only biomarker used as a screening tool clinically in routine practice. There is therefore an urgent need for new biomarkers to be used alongside, or in place of, PSA to optimise the diagnostic pathway, ensuring only men who are likely to benefit from treatment are screened, i.e. screening tests with the ability to identify men at highest risk of developing clinically significant and potentially life-limiting tumours.

As described above, certain groups of men have a higher risk of early onset and aggressive PrCa. Table 1 summarises the current international PrCa screening recommendations for higher risk groups. Most screening advisory bodies recommend PSA screening for men with a FH of PrCa and men of African ancestry, with the EAU recently updating their screening guidelines to include yearly PSA screening in men with pathogenic germline $B R C A 2$ variants from age 40 [74]. 
Table 1 Summary of specific screening advice using PSA in specific high-risk groups and general population

\begin{tabular}{|c|c|c|c|c|}
\hline & $\begin{array}{l}\text { General } \\
\text { population } \\
\text { screening }\end{array}$ & $\begin{array}{l}\text { Screening in men } \\
\text { with a family history }\end{array}$ & Screening in Black men & $\begin{array}{l}\text { Screening in } \\
B R C A 2 \text { carriers }\end{array}$ \\
\hline American Urological Association ${ }^{1}$ & No & Yes from 40 years* & Yes from 40 years & Not specified \\
\hline American Cancer Society $^{2}$ & No & Yes from $40-45$ years & Yes from $40-45$ years & Not specified \\
\hline European Association of Urology ${ }^{3}$ & No & Yes from 45 years & Yes from 45 years & Yes from 40 years \\
\hline National Comprehensive Cancer Network (NCCN, USA) ${ }^{4}$ & $\begin{array}{l}\text { To consider } \\
\text { in all } \\
\text { men aged } \\
45-75\end{array}$ & Yes from 45 years & Yes from 45 years & Yes from 45 years \\
\hline National Institute of Health and Care Excellence $(\mathrm{UK})^{5}$ & No & Not specified & Not specified & Not specified \\
\hline US Preventive Services Taskforce ${ }^{6}$ & No & Not specified & Not specified & Not specified \\
\hline
\end{tabular}

The NCCN guidelines advise PrCa screening to start at age 45 for male $B R C A 2$ carriers and to consider the same for $B R C A 1$ carriers [60]. There are a number of screening studies in progress, which are stratifying men into different risk groups based on different risk factors and aiming to use this risk-stratification, to improve on using PSA screening alone. These studies are summarised as follows. We predict that screening guidelines will be expanded to include men with other germline variants over the coming years based on the results of these studies. The benefit of risk-stratifying men based on genetic markers is that they are stable throughout a man's lifetime and not influenced by disease processes.

${ }^{1}$ https://www.auanet.org/guidelines/guidelines/prostatecancer-early-detection-guideline\#x2638

${ }^{2}$ https://www.cancer.org/cancer/prostate-cancer/detectiondiagnosis-staging/acs-recommendations.html

${ }^{3}$ https://uroweb.org/guideline/prostate-cancer/

${ }^{4}$ https://www.nccn.org/guidelines/guidelines-detail? category $=2 \& \mathrm{id}=1460$

${ }^{5}$ https://www.nice.org.uk/guidance/ng131

${ }^{6}$ https://www.uspreventiveservicestaskforce.org/uspstf/ recommendation/prostate-cancer-screening

\section{Screening in Carriers of Rare Variants}

\section{$B R C A 1$ and $B R C A 2$}

The IMPACT study (https://clinicaltrials.gov/ct2/show/ NCT00261456) has been underway since 2014 to assess the utility of targeted PSA screening for early diagnosis in germline BRCA1 and BRCA2 pathogenic variant carriers [34, 75]. A total of 2932 men (919 BRCA1 and 909 BRCA2 pathogenic variant carriers) aged 40-69 were enrolled for annual PSA screening, with prostate biopsy indicated where PSA is $>3.0 \mathrm{ng} / \mathrm{ml}$. IMPACT was the first prospective study to use germline genetic markers for identifying men with a high risk of PrCa. After 3 years of screening, men with a pathogenic variant in $B R C A 2$ were found to have a higher incidence of PrCa per 1000 person years (19.4 vs 12.0; $p=0.03$ ), were younger at diagnosis (61 vs 64 years; $p=0.04$ ) and had more clinically significant disease $(77 \%$ vs $40 \% ; p=0.01)$ compared with non-carriers. Therefore, the results of IMPACT so far confirm that PSA screening achieves early detection of aggressive $\mathrm{PrCa}$ in $B R C A 2$ carriers. The results of the full 5 years of screening are required to confirm the role of screening in men with pathogenic variants in BRCAI and to help develop the optimal screening strategy. Segal et al., in 2020, reported their first round of PrCa screening in $B R C A 1$ and BRCA 2 carriers, using an approach combining age-stratified PSA and MRI. They found a cancer detection rate of $8.6 \%$, with a significant benefit of screening using MRI compared to PSA in young men aged 40-55, whereas PSA had the highest benefit in those aged $>55$ [76].

\section{Mismatch Repair Genes}

The IMPACT study was extended to include a cohort of men with MMR genes MSH2, MSH6 and MLH1 using the same screening algorithm as above. The cohort of 828 participants has completed recruitment and includes $204 \mathrm{MLH} 1$ carriers, 305 MSH 2 carriers and 135 MSH6 carriers and 586 controls (men who had tested negative for a known familial pathogenic variant). Annual PSA screening will continue until 2024, and the baseline results are to be due to be submitted for publication imminently (Bancroft et al., 2021; personal communication). This will be the first published prospective screening study in men with pathogenic variants in these MMR genes.

\section{Screening Using Common Variants}

Using modelling, there is evidence to suggest that incorporating common variants into risk-stratification, and screening 
models could improve PrCa detection. Xu et al. (2009) built a risk-prediction model using 14 known $\mathrm{PrCa}$-associated SNPs together with FH [77]. They found an odds ratio of 4.92 for developing $\mathrm{PrCa}$ for men with a positive $\mathrm{FH}$ and with $\geq 14$ risk alleles [77]. Zheng et al. evaluated the effect of five SNPs associated with PrCa in a risk model combining FH and found their model accounted for $46 \%$ of PrCa cases within their cohort, with an odds ratio of 9.46 compared with men with no risk factors; this risk was independent of PSA [78].

The PROFILE study (https://clinicaltrials.gov/ct2/show/ NCT02543905) is in progress, examining the role of upfront MRI and prostate biopsy (regardless of PSA) in men aged 40-69 from two high-risk groups: 350 men with a FH of PrCa and 350 men of Afro-Caribbean descent. The study aims to calculate each participant's PRS and determine the PRS score association with MRI/biopsy outcome and its utility in detecting clinically significant PrCa. Men declining MRI and biopsy will undergo yearly PSA screening for a minimum of 5 years.

The PROFILE pilot study evaluated 115 men of European ancestry with a FH to establish feasibility and acceptability of the protocol. One hundred men underwent prostate biopsy at study enrolment, and the results were correlated with clinical variables and PRS based on 71 SNPs. The study reported a cancer detection rate of $25 \%$, of which $48 \%$ were clinically significant cancers requiring radical treatment [79]. No association was detected between the PRS and biopsy outcome; however, this initial pilot study was not powered to detect this difference. The main study is using a more extensive PRS with $>150$ SNPs and will provide valuable data on the ability of the PRS to predict clinically significant disease and determine its utility in the screening of higher risk men.

\section{Stockholm 3}

The Stockholm 3 (STHLM3) study, a Swedish prospective screening study involving 58,818 participants, aged 50 to 69 years, compared two cohorts of men, one undergoing PSA only versus a cohort of men undergoing the STHLM3 model [80]. The STHLM3 model predicts the probability of clinically significant PrCa based on a combination of plasma protein biomarkers (PSA, free PSA, intact PSA, hK2, MSMB, MIC1), genetic variants (232 SNPs) and clinical variables (age, $\mathrm{FH}$, previous prostate biopsy, prostate examination). They demonstrated that compared with offering biopsy to all men with a PSA $>3.0 \mathrm{ng} / \mathrm{mL}$, the STHLM3 model decreased overdiagnosis by avoiding $32 \%$ of prostate biopsies without significantly decreasing sensitivity to detect high-grade disease (Gleason $\geq 7$ ) and reducing the number of low-grade cancers (Gleason $\leq 6)$ detected by $17 \%$ [80]. The model has been shown to be cost-effective compared with a screening programme based on PSA alone [81]. However, all biomarkers in the model were added in one step and so it is not possible to analyse the individual effect of each biomarker and understand the proportional contribution of each factor [82]. The effect of STHLM3 plus MRI has also been studied, demonstrating that by biopsying men with a positive STHLM3 and a positive MRI, 38\% of biopsies could have been avoided, and this would have missed only $8 \%$ of all clinically significant PrCa compared with using MRI alone [83]. The STHLM3-MRI study is underway to determine whether use of MRI-fusion within the study algorithm can further refine and improve the diagnostic pathway [84].

\section{BARCODE1 Study}

The BARCODE1 study (https://www.clinicaltrials.gov/ct2/ show/NCT03857477) is the first prospective study to assess utility of PRS genetic profiling in a general practice setting for risk stratification. The study is enrolling men of European ancestry from General Practitioners (GPs) in the UK, to provide a DNA sample, from which the PRS is calculated using 130 PrCa risk SNPs. Men whose PRS puts them in the top $10 \%$ of the genetic risk distribution are invited to undergo screening with MRI and prostate biopsy, and those with negative screening tests continue annual PSA for 5 years. The study aims to recruit a total of 5000 men.

\section{Impact of Genetic Status on Treatments and Outcomes}

Most men with PrCa present with localised and treatable disease; however, the classification of tumour characteristics into low, intermediate or high-risk of metastasis at diagnosis is important for informing treatment strategy [85]. Indolent cancers are usually treated with active surveillance, whereas those with aggressive features warrant more intensive treatments such as surgery, radiotherapy or focal therapies \pm adjuvant therapies with hormones and chemotherapy. From a treatment perspective, knowing germline pathogenic variant status is increasingly important, particularly within the metastatic PrCa context. There is potential for the use of genetic testing at diagnosis to alter the treatment pathway in men with localised disease with data to suggest that for men on active surveillance, there is a higher upgrading on rebiopsy in men with germline pathogenic variants in ATM, BRCA1 or BRCA2 compared with non-carriers [20]. Therefore, men undergoing active surveillance identified with a high-risk pathogenic variant would be preferentially offered radical treatment. Approximately, one-third of men receiving treatment such as surgery or radiotherapy with curative intent will experience a recurrence of their cancer 
[86]. Germline pathogenic variants in DNA repair genes, BRCA1, BRCA2 and ATM, have been associated with aggressive behaviour of localised PrCa, cancer-specific mortality and death from $\mathrm{PrCa}$ at a younger age [22, 25, 31, 87]. Therefore, when considering treatment options, the presence of germline pathogenic variants should be taken into account and should steer clinicians away from opting for active surveillance in favour of surgery in men with $\mathrm{PrCa}$ and a pathogenic germline variant $[20,36]$.

Castro et al. investigated the tumour characteristics and treatment outcomes in a cohort of 1302 men with PrCa, including 67 men with germline $B R C A 1$ and $B R C A 2$ pathogenic variants. They found that $B R C A 1$ and $B R C A 2$ pathogenic variant carriers had more aggressive tumours, higher $\mathrm{T}$ scores, higher Gleason scores and more frequent nodal involvement, developing metastasis sooner and having shorter overall and cause-specific survival at 10 years compared with non-carriers. Of those treated with curative intent, treated with either radical prostatectomy or radiotherapy, there was no significant difference detected in PrCa-specific survival between $B R C A 1$ and $B R C A 2$ carriers and non-carriers who underwent prostatectomy; conversely, there was a significant difference in PrCa-specific survival detected between $B R C A 1$ and $B R C A 2$ carriers and non-carriers who underwent radiotherapy [21,22]. These retrospective studies had a relatively small number of $B R C A 1$ and $B R C A 2$ carriers, and further evaluation within the GENPROS study (https://clinicaltrials.gov/ct2/ show/NCT02705846) aims to assess the clinical outcomes in men with $\mathrm{PrCa}$ and germline pathogenic variants in PrCa predisposition genes, including the $B R C A 1, B R C A 2$, ATM, CHEK2, PALB2, HOXB13 and MMR genes (MSH2, MSH6, MLH1, PMS2) amongst others.

\section{PARP Inhibitors}

The PARP-inhibitor Olaparib is approved for the treatment of advanced ovarian and breast cancers associated with germline $B R C A 1$ or $B R C A 2$ pathogenic variants [88]. The use of olaparib in men with metastatic castration-resistant $\mathrm{PrCa}$ (mCRPC) with germline or somatic pathogenic variants in $B R C A 1$ or $B R C A 2$ has been evaluated in the TOPARP studies $[24,89]$. These studies confirmed that PARP inhibitors are associated with an increased response rate in this subgroup of men. TOPARP-B also identified a potential role for PARP inhibitors for men with metastatic disease with somatic or germline pathogenic variants in ATM, PALB2, $F A N C A$ or $C H E K 2$, although further data are needed to precisely assess the clinical benefit for each gene. PARP inhibitors are now licensed in the USA and Europe for men with germline pathogenic variants in DNA repair genes, specifically BRCA1, BRCA2 and ATM [39, 89, 90].

\section{Immune Checkpoint Inhibitors}

Men with prostate tumours that are MMR deficient are known to be sensitive to immune checkpoint inhibitors [91, 92]. The Philadelphia Prostate Cancer Consensus (2017) recommended that men with PrCa and a FH of Lynch Syndrome should be screened for MMR gene variants, and men whose prostate tumour contains pathogenic variants in MMR genes should undergo germline testing [93]. The NCCN guidelines support the use of pembrolizumab in patients with MMR-deficient metastatic castrate-resistant PrCa whose disease has progressed on at least one line of treatment $[94,95]$.

\section{Platinum Chemotherapy}

Men with $\mathrm{PrCa}$ and pathogenic variants in BRCAl, $B R C A 2$ and other DNA repair genes have also shown an increased sensitivity to platinum chemotherapy [96-98]. $B R C A 1 / B R C A 2$ pathogenic variant status is known to predict response to platinum-based chemotherapies in other cancers, predominantly breast and ovarian cancer, but they are not routinely used to treat PrCa due to a lack of proven clinical benefit in unselected populations [99]. There are data to support a similar response in men with mCRPC who have a germline variant in a DNA repair gene and especially in patients with $\mathrm{mCRPC}$ and $B R C A 2$ pathogenic variants [97, 98]. The BARCODE2 study (https://clinicaltrials.gov/ ct2/show/NCT02955082) is aiming to investigate response to carboplatin in men with mCRPC who have completed all lines of standard treatment and who harbour germline pathogenic variants in a DNA repair gene, some of which have not previously been assessed in the above trials. Platinum chemotherapy is an attractive prospect as it has the advantage of being readily and cheaply available within Oncology.

\section{Conclusions}

The importance of understanding germline genetic variation and its role in identifying men at increased risk of $\mathrm{PrCa}$ for targeted screening and informing targeted treatment decisions in men with advanced disease is becoming increasingly recognised [9]. A combination of common and rare variants is likely to influence risk of $\mathrm{PrCa}$, with common variants conferring a substantial contribution at the general population level and rare variants specific to certain families or populations.

Studies are showing the promise of PRS within a $\mathrm{PrCa}$ screening algorithm for risk-stratification and facilitation of early detection of $\mathrm{PrCa}$ in men at higher risk. Both men with a FH and those of African ancestry have a susceptibility to earlier onset and more aggressive disease making 
them ideal cohorts to establish robust screening protocols to improve early diagnosis and treatment. However, whilst studies assessing the feasibility of using genetics for targeted screening exist, further research is required, particularly in respect to our understanding of the contribution of common variants across diverse ethnic groups, to be able to offer genetic risk assessments at a general population level [9]. Additionally, the contribution of common variants towards risk of aggressive disease individually or cumulatively requires further research.

There is growing demand from patients for routine integration of genetics into oncological care. Whilst such routine integration has been achieved within ovarian and breast cancer, there is huge potential for a similar model to be implemented in PrCa. We anticipate that the routine use of genetic testing, incorporating both common and rare variants, will be integrated into PrCa screening and management protocols within the next 5 years internationally. This integration will have a direct impact on PrCa screening accuracy and efficiency, early diagnosis and treatment options, and ultimately will improve PrCa survival in the highest-risk populations of men, together with inevitable health economic and psychological benefits $[7 \bullet, 20 \bullet, 23 \bullet, 26,27,28,34 \bullet, 42 \bullet, 49$, $50,51,52 \bullet, 57 \bullet, 61,64 \bullet, 69 \bullet, 76 \bullet \bullet, 83 \bullet]$.

Funding The authors are supported by grants awarded by the National Institute of Health Research, Cancer Research UK, Prostate Cancer UK, Movember Centre of Excellence and the European Research Council. We received funding from the National Institute for Health Research (NIHR) to the Biomedical Research Centre at The Institute of Cancer Research and the Royal Marsden NHS Foundation Trust.

\section{Declarations}

Conflict of Interest E. Bancroft, H. Ni Raghallaigh and E. Page have no conflicts of interest to disclose. Prof Eeles reports personal fees from AstraZeneca UK Limited for her role as a member of external Expert Committee as part of the Prostate Cancer Diagnosis Advisory Panel, and University of Chicago for an invited lecture, both of which are outside the submitted work.

Human and Animal Rights All reported studies/experiments with human or animal subjects performed by the authors have been previously published and complied with all applicable ethical standards (including the Helsinki Declaration and its amendments, institutional/ national research committee standards, and international/national/institutional guidelines).

Open Access This article is licensed under a Creative Commons Attribution 4.0 International License, which permits use, sharing, adaptation, distribution and reproduction in any medium or format, as long as you give appropriate credit to the original author(s) and the source, provide a link to the Creative Commons licence, and indicate if changes were made. The images or other third party material in this article are included in the article's Creative Commons licence, unless indicated otherwise in a credit line to the material. If material is not included in the article's Creative Commons licence and your intended use is not permitted by statutory regulation or exceeds the permitted use, you will need to obtain permission directly from the copyright holder. To view a copy of this licence, visit http://creativecommons.org/licenses/by/4.0/.

\section{References}

\section{Papers of particular interest, published recently, have been highlighted as: \\ - Of importance \\ $\bullet$ Of major importance}

1. Bray F, Ferlay J, Soerjomataram I, Siegel RL, Torre LA, Jemal A. Global cancer statistics 2018: GLOBOCAN estimates of incidence and mortality worldwide for 36 cancers in 185 countries. CA Cancer J Clin. 2018;68(6):394-424. https://doi.org/10.3322/ caac. 21492.

2. Cancer Research UK. Prostate cancer statistics. 2021. https:// www.cancerresearchuk.org/health-professional/cancer-statistics/ statistics-by-cancer-type/prostate-cancer. Accessed 01/05/2021.

3. Global Cancer Observatory. Prostate Fact Sheet. 2020. https://gco. iarc.fr/today/online-analysis-table Accessed 01/05/2021.

4. Siegel RL, Miller KD, Jemal A. Cancer statistics, 2020. CA Cancer J Clin. 2020;70(1):7-30. https://doi.org/10.3322/caac.21590.

5. Taitt HE. Global trends and prostate cancer: a review of incidence, detection, and mortality as influenced by race, ethnicity, and geographic location. Am J Mens Health. 2018;12(6):1807-23. https:// doi.org/10.1177/1557988318798279.

6. DeSantis CE, Miller KD, Goding Sauer A, Jemal A, Siegel RL. Cancer statistics for African Americans, 2019. CA Cancer J Clin. 2019;69(3):211-33. https://doi.org/10.3322/caac.21555.

7. Dess RT, Hartman HE, Mahal BA, Soni PD, Jackson WC, Cooperberg MR et al. Association of Black Race With Prostate Cancer-Specific and Other-Cause Mortality. JAMA Oncol. 2019;5(7):975-83. https://doi.org/10.1001/jamaoncol.2019.0826. Association of black race with long-term prostate cancer survival outcomes; and sociodemographic disparities.

8. McGinley KF, Tay KJ, Moul JW. Prostate cancer in men of African origin. Nat Rev Urol. 2016;13(2):99-107. https://doi.org/10. 1038/nrurol.2015.298.

9. Saunders EJ, Kote-Jarai Z, Eeles RA. Identification of germline genetic variants that increase prostate cancer risk and influence development of aggressive disease. Cancers. 2021;13(4). https:// doi.org/10.3390/cancers13040760.

10. Hjelmborg JB, Scheike T, Holst K, Skytthe A, Penney KL, Graff RE, et al. The heritability of prostate cancer in the Nordic Twin Study of Cancer. Cancer Epidemiol Biomarkers Prev. 2014;23(11):2303-10. https://doi.org/10.1158/1055-9965. EPI-13-0568.

11. Albright FS, Stephenson RA, Agarwal N, Cannon-Albright LA. Relative risks for lethal prostate cancer based on complete family history of prostate cancer death. Prostate. 2017;77(1):41-8. https://doi.org/10.1002/pros.23247.

12. Bratt O, Drevin L, Akre O, Garmo H, Stattin P. Family history and probability of prostate cancer, differentiated by risk category: a nationwide population-based study. J Natl Cancer Inst. 2016;108(10). https://doi.org/10.1093/jnci/djw110.

13. Kupelian PA, Klein EA, Witte JS, Kupelian VA, Suh JH. Familial prostate cancer: a different disease? J Urol. 1997;158(6):2197201. https://doi.org/10.1016/s0022-5347(01)68194-1.

14. Barber L, Gerke T, Markt SC, Peisch SF, Wilson KM, Ahearn $\mathrm{T}$, et al. Family history of breast or prostate cancer and prostate cancer risk. Clin Cancer Res. 2018;24(23):5910-7. https://doi.org/ 10.1158/1078-0432.CCR-18-0370. 
15. Pritchard CC. New name for breast-cancer syndrome could help to save lives. Nature. 2019;571(7763):27-9. https://doi.org/10.1038/ d41586-019-02015-7.

16. Benafif S, Kote-Jarai Z, Eeles RA, Consortium P. A review of prostate cancer genome-wide association studies (GWAS). Cancer Epidemiol Biomarkers Prev. 2018;27(8):845-57. https://doi.org/ 10.1158/1055-9965.EPI-16-1046.

17. Dias A, Kote-Jarai Z, Mikropoulos C, Eeles R. Prostate cancer germline variations and implications for screening and treatment. Cold Spring Harb Perspect Med. 2018;8(9). https://doi.org/10. 1101/cshperspect.a030379.

18. Eeles R, Ni RH. Men with a susceptibility to prostate cancer and the role of genetic based screening. Transl Androl Urol. 2018;7(1):61-9. https://doi.org/10.21037/tau.2017.12.30.

19. McCarthy MI, Abecasis GR, Cardon LR, Goldstein DB, Little J, Ioannidis JPA, et al. Genome-wide association studies for complex traits: consensus, uncertainty and challenges. Nat Rev Genet. 2008;9(5):356-69. https://doi.org/10.1038/nrg2344.

20. Carter HB, Helfand B, Mamawala M, Wu Y, Landis P, Yu H et al. Germline mutations in ATM and BRCA1/2 are associated with grade reclassification in men on active surveillance for prostate cancer. Eur Urol. 2019;75(5):743-9. https://doi.org/10. 1016/j.eururo.2018.09.021. Germline mutations in ATM and BRCA1/2 are associated with grade reclassification in men on active surveillance for prostate cancer. Eur. Urol. 2019, 75, 743-749. Active surveillance in men with high-risk germline mutations should be considered with caution.

21. Castro E, Goh C, Leongamornlert D, Saunders E, Tymrakiewicz M, Dadaev T, et al. Effect of BRCA Mutations on metastatic relapse and cause-specific survival after radical treatment for localised prostate cancer. Eur Urol. 2015;68(2):186-93. https:// doi.org/10.1016/j.eururo.2014.10.022.

22. Castro E, Goh C, Olmos D, Saunders E, Leongamornlert D, Tymrakiewicz M, et al. Germline BRCA mutations are associated with higher risk of nodal involvement, distant metastasis, and poor survival outcomes in prostate cancer. Journal of clinical oncology : official journal of the American Society of Clinical Oncology. 2013;31(14):1748-57. https://doi.org/10.1200/JCO. 2012.43.1882.

23. Leongamornlert DA, Saunders EJ, Wakerell S, Whitmore I, Dadaev T, Cieza-Borrella C et al. Germline DNA repair gene mutations in young-onset prostate cancer cases in the UK: evidence for a more extensive genetic Panel. Eur Urol. 2019;76(3):329-37. https://doi.org/10.1016/j.eururo.2019. Evidence for a more extensive genetic panel. Eur. Urol. 2019, 76, 329-337. Large sequencing study identified 23 DNA repair genes associated with PrCa predisposition or risk of aggressive disease.

24. Mateo J, Carreira S, Sandhu S, Miranda S, Mossop H, PerezLopez R, et al. DNA-repair defects and olaparib in metastatic prostate cancer. N Engl J Med. 2015;373(18):1697-708. https:// doi.org/10.1056/NEJMoa1506859.

25. Na R, Zheng SL, Han M, Yu H, Jiang D, Shah S, et al. Germline Mutations in ATM and BRCA1/2 distinguish risk for lethal and indolent prostate cancer and are associated with early age at death. Eur Urol. 2017;71(5):740-7. https://doi.org/10.1016/j.eururo. 2016.11.033.

26. Nyberg T, Frost D, Barrowdale D, Evans DG, Bancroft E, Adlard $\mathrm{J}$, et al. Prostate cancer risks for male BRCA1 and BRCA2 mutation carriers: a prospective cohort study. Eur Urol. 2020;77(1):24 35. https://doi.org/10.1016/j.eururo.2019.08.025.

27. Pritchard CC, Mateo J, Walsh MF, De Sarkar N, Abida W, Beltran $\mathrm{H}$, et al. Inherited DNA-repair gene mutations in men with metastatic prostate cancer. N Engl J Med. 2016;375(5):443-53. https:// doi.org/10.1056/NEJMoa1603144.
28. Robinson D, Van Allen EM, Wu YM, Schultz N, Lonigro RJ, Mosquera JM, et al. Integrative clinical genomics of advanced prostate cancer. Cell. 2015;162(2):454. https://doi.org/10.1016/j. cell.2015.06.053.

29. Zhen JT, Syed J, Nguyen KA, Leapman MS, Agarwal N, Brierley $\mathrm{K}$, et al. Genetic testing for hereditary prostate cancer: current status and limitations. Cancer. 2018;124(15):3105-17. https://doi. org/10.1002/cncr.31316.

30. Edwards SM, Kote-Jarai Z, Meitz J, Hamoudi R, Hope Q, Osin $\mathrm{P}$, et al. Two percent of men with early-onset prostate cancer harbor germline mutations in the BRCA2 gene. Am J Hum Genet. 2003;72(1):1-12. https://doi.org/10.1086/345310.

31. Kote-Jarai Z, Leongamornlert D, Saunders E, Tymrakiewicz M, Castro E, Mahmud N, et al. BRCA2 is a moderate penetrance gene contributing to young-onset prostate cancer: implications for genetic testing in prostate cancer patients. Br J Cancer. 2011;105(8):1230-4.

32. van Asperen CJ, Brohet RM, Meijers-Heijboer EJ, Hoogerbrugge $\mathrm{N}$, Verhoef S, Vasen HF, et al. Cancer risks in BRCA2 families: estimates for sites other than breast and ovary. J Med Genet. 2005;42(9):711-9. https://doi.org/10.1136/jmg.2004.028829.

33. Akbari MR, Wallis CJ, Toi A, Trachtenberg J, Sun P, Narod SA, et al. The impact of a BRCA2 mutation on mortality from screendetected prostate cancer. Br J Cancer. 2014;111(6):1238-40. https://doi.org/10.1038/bjc.2014.428.

34. Page EC, Bancroft EK, Brook MN, Assel M, Hassan Al Battat M, Thomas $S$ et al. Interim results from the IMPACT Study: evidence for prostate-specific antigen screening in BRCA2 mutation carriers. Eur Urol. 2019;76(6):831-42. https://doi.org/10.1016/j. eururo.2019.08.019. Evidence for yearly PSA screening detecting clinically significant tumours in BRCA2 carriers.

35. Taylor RA, Fraser M, Livingstone J, Espiritu SM, Thorne H, Huang V, et al. Germline BRCA2 mutations drive prostate cancers with distinct evolutionary trajectories. Nat Commun. 2017;8:13671. https://doi.org/10.1038/ncomms13671.

36. Wu Y, Yu H, Li S, Wiley K, Zheng SL, LaDuca H, et al. Rare germline pathogenic mutations of DNA repair genes are most strongly associated with grade group 5 prostate cancer. Eur Urol Oncol. 2020;3(2):224-30. https://doi.org/10.1016/j.euo.2019.12.003.

37. Leongamornlert D, Mahmud N, Tymrakiewicz M, Saunders E, Dadaev T, Castro E, et al. Germline BRCA1 mutations increase prostate cancer risk. Br J Cancer. 2012;106(10):1697-701. https:// doi.org/10.1038/bjc.2012.146.

38. Thompson D, Easton DF. Cancer incidence in BRCA1 mutation carriers. J Natl Cancer Inst. 2002;94(18):1358-65.

39. Karlsson Q, Brook MN, Dadaev T, Wakerell S, Saunders EJ, Muir $\mathrm{K}$ et al. Rare germline variants in ATM predispose to prostate cancer: A PRACTICAL Consortium Study. Eur Urol Oncol. 2021. https://doi.org/10.1016/j.euo.2020.12.001. Carriers of pathogenic ATM variants have an elevated risk of developing PrCa and are at an increased risk for earlier-onset disease.

40. Brandao A, Paulo P, Teixeira MR. Hereditary predisposition to prostate cancer: from genetics to clinical implications. Int J Mol Sci. 2020;21(14). https://doi.org/10.3390/ijms21145036.

41. Naslund-Koch C, Nordestgaard BG, Bojesen SE. Increased risk for other cancers in addition to breast cancer for CHEK $2 * 1100$ delC heterozygotes estimated from the copenhagen general population study. Journal of clinical oncology : official journal of the American Society of Clinical Oncology. 2016;34(11):1208-16. https:// doi.org/10.1200/JCO.2015.63.3594.

42.• Darst BF, Wan P, Sheng X, Bensen JT, Ingles SA, Rybicki BA et al. A germline variant at $8 \mathrm{q} 24$ contributes to familial clustering of prostate cancer in men of African ancestry. Eur Urol. 2020;78(3):316-20. https://doi.org/10.1016/j.eururo.2020.04.060. A specific PrCa risk variant exists in men with African ancestry with early onset PrCa and in those with a family history 
of PrCa, meaning black men may benefit from knowing if they carry this risk SNP to inform future PrCa screening decisions.

43. Ewing CM, Ray AM, Lange EM, Zuhlke KA, Robbins CM, Tembe WD, et al. Germline mutations in HOXB13 and prostatecancer risk. N Engl J Med. 2012;366(2):141-9. https://doi.org/10. 1056/NEJMoa1110000.

44. Karlsson R, Aly M, Clements M, Zheng L, Adolfsson J, Xu J, et al. A population-based assessment of germline HOXB13 G84E mutation and prostate cancer risk. Eur Urol. 2014;65(1):169-76. https://doi.org/10.1016/j.eururo.2012.07.027.

45. Nyberg T, Govindasami K, Leslie G, Dadaev T, Bancroft E, Ni Raghallaigh H, et al. Homeobox B13 G84E mutation and prostate cancer risk. Eur Urol. 2019;75(5):834-45. https://doi. org/10.1016/j.eururo.2018.11.015.

46. Barrow PJ, Ingham S, O'Hara C, Green K, McIntyre I, Lalloo $\mathrm{F}$, et al. The spectrum of urological malignancy in Lynch syndrome. Fam Cancer. 2013;12(1):57-63. https://doi.org/10.1007/ s10689-012-9573-z.

47. Dominguez-Valentin M, Joost P, Therkildsen C, Jonsson M, Rambech E, Nilbert M. Frequent mismatch-repair defects link prostate cancer to Lynch syndrome. BMC Urol. 2016;16:15. https://doi.org/10.1186/s12894-016-0130-1.

48. Grindedal EM, Moller P, Eeles R, Stormorken AT, BowitzLothe IM, Landro SM, et al. Germ-line mutations in mismatch repair genes associated with prostate cancer. Cancer Epidemiol Biomarkers Prev. 2009;18(9):2460-7. https://doi.org/10.1158/ 1055-9965.EPI-09-0058.

49. Haraldsdottir S, Hampel H, Wei L, Wu C, Frankel W, BekaiiSaab T, et al. Prostate cancer incidence in males with Lynch syndrome. Genetics in medicine : official journal of the American College of Medical Genetics. 2014;16(7):553-7. https://doi. org/10.1038/gim.2013.193.

50. Ryan S, Jenkins MA, Win AK. Risk of prostate cancer in Lynch syndrome: a systematic review and meta-analysis. Cancer Epidemiol Biomarkers Prev. 2014;23(3):437-49. https://doi.org/10. 1158/1055-9965.EPI-13-1165.

51. Rosty C, Walsh MD, Lindor NM, Thibodeau SN, Mundt E, Gallinger S, et al. High prevalence of mismatch repair deficiency in prostate cancers diagnosed in mismatch repair gene mutation carriers from the colon cancer family registry. Fam Cancer. 2014;13(4):573-82. https://doi.org/10.1007/ s10689-014-9744-1.

52.• Dominguez-Valentin M, Sampson JR, Seppala TT, Ten Broeke SW, Plazzer JP, Nakken S et al. Cancer risks by gene, age, and gender in 6350 carriers of pathogenic mismatch repair variants: findings from the Prospective Lynch Syndrome Database. Genetics in medicine : official journal of the American College of Medical Genetics. 2020;22(1):15-25. https://doi.org/10.1038/s41436019-0596-9. Older men who carry pathogenic MSH2 variants are at higher risk of PrCa than previously thought.

53. Engel C, Loeffler M, Steinke V, Rahner N, Holinski-Feder E, Dietmaier W, et al. Risks of less common cancers in proven mutation carriers with lynch syndrome. Journal of clinical oncology : official journal of the American Society of Clinical Oncology. 2012;30(35):4409-15. https://doi.org/10.1200/JCO.2012.43.2278.

54. Win AK, Lindor NM, Young JP, Macrae FA, Young GP, Williamson $\mathrm{E}$, et al. Risks of primary extracolonic cancers following colorectal cancer in lynch syndrome. J Natl Cancer Inst. 2012;104(18):136372. https://doi.org/10.1093/jnci/djs351.

55. Cybulski C, Wokolorczyk D, Kluzniak W, Jakubowska A, Gorski B, Gronwald J, et al. An inherited NBN mutation is associated with poor prognosis prostate cancer. Br J Cancer. 2013;108(2):461-8. https://doi.org/10.1038/bjc.2012.486.

56. Leongamornlert D, Saunders E, Dadaev T, Tymrakiewicz M, Goh C, Jugurnauth-Little S, et al. Frequent germline deleterious mutations in DNA repair genes in familial prostate cancer cases are associated with advanced disease. Br J Cancer. 2014;110(6):1663-72. https://doi.org/10.1038/bjc.2014.30.

57.• Giri VN, Knudsen KE, Kelly WK, Cheng HH, Cooney KA, Cookson MS et al. Implementation of germline testing for prostate cancer: Philadelphia Prostate Cancer Consensus Conference 2019. Journal of clinical oncology : official journal of the American Society of Clinical Oncology. 2020;38(24):2798-811. https:// doi.org/10.1200/JCO.20.00046. Philadelphia prostate cancer consensus conference 2019. J. Clin. Oncol. 2020. Multidisciplinary US Consensus-driven genetic implementation framework for precision medicine in prostate cancer: guidance to clinicians and patients.

58. National Comprehensive Cancer Network. NCCN Clinical Practice Guidelines in Oncology: Prostate Cancer. Version 2. 2021. Feb 17, 2021 2021. https://www.nccn.org/guidelines/guidelinesdetail?category=1\&id=1459. Accessed 01/05/2021.

59. Evans D, Harkness E, Plaskocinska I, Wallace A, Clancy T, Woodward E et al. Pathology update to the Manchester Scoring System based on testing in over 4000 families. Journal of Medical Genetics. 2017 Oct 1;2017(54). https://doi.org/10.1136/ jmedgenet-2017-104584

60. National Comprehensive Cancer Network. NCCN Clinical Practice Guidelines in Oncology: Prostate Cancer Early Detection. Version 1. 2021. Jan 5,2021 2021. https://www.nccn.org/ guidelines/guidelines-detail? category $=2 \& \mathrm{id}=1460$. Accessed 01/05/2021.

61. National Comprehensive Cancer Network. NCCN Clinical Practice Guidelines in Oncology: Prostate Cancer. Genetic/Familial highrisk assessment: Breast, Ovarian and Pancreatic. Version 2. 2021. Nov 20, 2020. 2020. https://www.nccn.org/guidelines/guidelinesdetail?category $=2 \& \mathrm{id}=1436$. Accessed 01/05/2021.

62. Schumacher FR, Al Olama AA, Berndt SI, Benlloch S, Ahmed M, Saunders EJ, et al. Association analyses of more than 140,000 men identify 63 new prostate cancer susceptibility loci. Nat Genet. 2018;50(7):928-36. https://doi.org/10.1038/s41588-018-0142-8.

63. Dadaev T, Saunders EJ, Newcombe PJ, Anokian E, Leongamornlert DA, Brook MN, et al. Fine-mapping of prostate cancer susceptibility loci in a large meta-analysis identifies candidate causal variants. Nat Commun. 2018;9(1):2256. https://doi.org/10.1038/ s41467-018-04109-8.

64. Callender T, Emberton M, Morris S, Eeles R, Kote-Jarai Z, Pharoah PDP et al. Polygenic risk-tailored screening for prostate cancer: a benefit-harm and cost-effectiveness modelling study. PLoS Med. 2019;16(12):e1002998. https://doi.org/10.1371/journal.pmed. 1002998. Health Economic evaluation of use of PRS in prostate cancer screening.

65. Conti DV, Darst BF, Moss LC, Saunders EJ, Sheng X, Chou A et al. Trans-ancestry genome-wide association meta-analysis of prostate cancer identifies new susceptibility loci and informs genetic risk prediction. Nat Genet. 2021;53(1):65-75. https://doi. org/10.1038/s41588-020-00748-0. Trans-ancestry genome-wide association meta-analysis of prostate cancer identifies new susceptibility loci and informs genetic risk prediction.

66. Lecarpentier J, Silvestri V, Kuchenbaecker KB, Barrowdale D, Dennis J, McGuffog L et al. Prediction of breast and prostate cancer risks in male BRCA1 and BRCA2 mutation carriers using polygenic risk scores. Journal of clinical oncology : official journal of the American Society of Clinical Oncology. 2017;35(20):2240-50. https://doi.org/10.1200/JCO.2016.69. 4935. A PRS can further risk stratify men with pathogenic BRCA1/2 variants, with large differences in PrCa risk seen in men at the extremes of the polygenic risk distribution.

67. Carter JL, Coletti RJ, Harris RP. Quantifying and monitoring overdiagnosis in cancer screening: a systematic review of methods. BMJ. 2015;350: g7773. https://doi.org/10.1136/bmj.g7773. 
68. Tikkinen KAO, Dahm P, Lytvyn L, Heen AF, Vernooij RWM, Siemieniuk RAC, et al. Prostate cancer screening with prostatespecific antigen (PSA) test: a clinical practice guideline. BMJ. 2018;362: k3581. https://doi.org/10.1136/bmj.k3581.

69. Hugosson J, Roobol MJ, Mansson M, Tammela TLJ, Zappa M, Nelen $\mathrm{V}$ et al. A 16-yr follow-up of the European randomized study of screening for prostate cancer. Eur Urol. 2019;76(1):4351. https://doi.org/10.1016/j.eururo.2019.02.009. Report on 16 year's follow-up in the European randomised study of screening for prostate cancer; repeated PSA screening reduces risk of dying from prostate cancer.

70. Schroder FH, Hugosson J, Roobol MJ, Tammela TL, Zappa M, Nelen V, et al. Screening and prostate cancer mortality: results of the European Randomised Study of Screening for Prostate Cancer (ERSPC) at 13 years of follow-up. Lancet. 2014;384(9959):2027-35. https://doi.org/10.1016/S01406736(14)60525-0.

71. Andriole GL, Crawford ED, Grubb RL 3rd, Buys SS, Chia D, Church TR, et al. Prostate cancer screening in the randomized prostate, lung, colorectal, and ovarian cancer screening trial: mortality results after 13 years of follow-up. J Natl Cancer Inst. 2012;104(2):125-32. https://doi.org/10.1093/jnci/djr500.

72. Pinsky PF, Miller E, Prorok P, Grubb R, Crawford ED, Andriole G. Extended follow-up for prostate cancer incidence and mortality among participants in the prostate, lung, colorectal and ovarian randomized cancer screening trial. BJU Int. 2019;123(5):854-60. https://doi.org/10.1111/bju.14580.

73. Koo KM, Mainwaring PN, Tomlins SA, Trau M. Merging newage biomarkers and nanodiagnostics for precision prostate cancer management. Nat Rev Urol. 2019;16(5):302-17. https://doi.org/ 10.1038/s41585-019-0178-2

74. European Association of Urology. 2020. https://uroweb.org/guideline/ prostate-cancer/ Accessed 01/05/2021.

75. Bancroft EK, Page EC, Castro E, Lilja H, Vickers A, Sjoberg D, et al. Targeted prostate cancer screening in BRCA1 and BRCA2 mutation carriers: results from the initial screening round of the IMPACT study. Eur Urol. 2014;66(3):489-99. https://doi.org/10. 1016/j.eururo.2014.01.003.

76.• Segal N, Ber Y, Benjaminov O, Tamir S, Yakimov M, Kedar I et al. Imaging-based prostate cancer screening among BRCA mutation carriers-results from the first round of screening. Ann Oncol. 2020;31(11):1545-52. https://doi.org/10.1016/j.annonc. 2020.06.025. Prostate MRI was more useful than PSA in men aged $<55$ years in a PrCa screening protocol for men with known BRCA2 pathogenic variants.

77. Xu J, Sun J, Kader AK, Lindstrom S, Wiklund F, Hsu FC, et al. Estimation of absolute risk for prostate cancer using genetic markers and family history. Prostate. 2009;69(14):1565-72. https://doi. org/10.1002/pros.21002.

78. Zheng SL, Sun J, Wiklund F, Smith S, Stattin P, Li G, et al. Cumulative association of five genetic variants with prostate cancer. N Engl J Med. 2008;358(9):910-9. https://doi.org/10.1056/ NEJMoa075819.

79. Castro E, Mikropoulos C, Bancroft EK, Dadaev T, Goh C, Taylor N, et al. The PROFILE feasibility study: targeted screening of men with a family history of prostate cancer. Oncologist. 2016;21(6):716-22. https://doi.org/10.1634/theoncologist.2015-0336.

80. Gronberg H, Adolfsson J, Aly M, Nordstrom T, Wiklund P, Brandberg Y, et al. Prostate cancer screening in men aged 50-69 years (STHLM3): a prospective population-based diagnostic study. Lancet Oncol. 2015;16(16):1667-76. https://doi.org/10. 1016/S1470-2045(15)00361-7

81. Karlsson AA, Hao S, Jauhiainen A, Elfstrom KM, Egevad L, Nordstrom T, et al. The cost-effectiveness of prostate cancer screening using the Stockholm3 test. PLoS ONE. 2021;16(2): e0246674. https://doi.org/10.1371/journal.pone.0246674.
82. Carlsson SV, Kattan MW. The STHLM3 prostate cancer diagnostic study: calibration, clarification, and comments. Nat Rev Clin Oncol. 2016;13(6). https://doi.org/10.1038/nrclinonc.2016.81.

83.• Gronberg H, Eklund M, Picker W, Aly M, Jaderling F, Adolfsson J et al. Prostate cancer diagnostics using a combination of the Stockholm3 blood test and multiparametric magnetic resonance imaging. Eur Urol. 2018;74(6):722-8. https://doi.org/10.1016/j.eururo. 2018.06.022. When the Stockholm3 test (which incorporates a PRS) was used to inform which men should undergo further intervention with a prostate MRI and biopsy, a reduction in overdiagnosis of indolent PrCa was noted without reducing the diagnosis of clinically significant disease.

84. Nordstrom T, Jaderling F, Carlsson S, Aly M, Gronberg H, Eklund M. Does a novel diagnostic pathway including blood-based risk prediction and MRI-targeted biopsies outperform prostate cancer screening using prostate-specific antigen and systematic prostate biopsies? - protocol of the randomised study STHLM3MRI. BMJ Open. 2019;9(6): e027816. https://doi.org/10.1136/bmjopen-2018-027816.

85. National Institute of Health and Clinical Excellence. Prostate cancer: diagnosis and management, NICE guideline, NG. 131. 2008.

86. Buyyounouski MK, Pickles T, Kestin LL, Allison R, Williams SG. Validating the interval to biochemical failure for the identification of potentially lethal prostate cancer. Journal of clinical oncology : official journal of the American Society of Clinical Oncology. 2012;30(15):1857-63. https://doi.org/10.1200/JCO.2011.35.1924.

87. Gallagher DJ, Gaudet MM, Pal P, Kirchhoff T, Balistreri L, Vora $\mathrm{K}$, et al. Germline BRCA mutations denote a clinicopathologic subset of prostate cancer. Clin Cancer Res. 2010;16(7):2115-21. https://doi.org/10.1158/1078-0432.CCR-09-2871.

88. Kaufman B, Shapira-Frommer R, Schmutzler RK, Audeh MW, Friedlander M, Balmana $\mathrm{J}$, et al. Olaparib monotherapy in patients with advanced cancer and a germline BRCA1/2 mutation. Journal of clinical oncology : official journal of the American Society of Clinical Oncology. 2015;33(3):244-50. https://doi.org/10.1200/ JCO.2014.56.2728.

89. Mateo J, Porta N, McGovern UB, Elliott T, Jones RJ, Syndikus I et al. TOPARP-B: a phase II randomized trial of the poly(ADP)ribose polymerase (PARP) inhibitor olaparib for metastatic castration resistant prostate cancers (mCRPC) with DNA damage repair (DDR) alterations. Journal of Clinical Oncology. 2019;37(15 suppl):5005. https://doi.org/10.1200/JCO.2019.37.15_suppl.5005.

90.• de Bono J, Mateo J, Fizazi K, Saad F, Shore N, Sandhu S et al. Olaparib for metastatic castration-resistant prostate cancer. N Engl J Med. 2020;382(22):2091-102. https://doi.org/10.1056/ NEJMoa1911440. The use of Olaparib in men with pathogenic variants in DNA repair genes.

91. Antonarakis ES, Shaukat F, Isaacsson Velho P, Kaur H, Shenderov E, Pardoll DM, et al. Clinical features and therapeutic outcomes in men with advanced prostate cancer and DNA mismatch repair gene mutations. Eur Urol. 2019;75(3):378-82. https://doi.org/10. 1016/j.eururo.2018.10.009.

92. Le DT, Durham JN, Smith KN, Wang H, Bartlett BR, Aulakh LK, et al. Mismatch repair deficiency predicts response of solid tumors to PD-1 blockade. Science. 2017;357(6349):409-13. https://doi. org/10.1126/science.aan6733.

93. Giri VN, Knudsen KE, Kelly WK, Abida W, Andriole GL, Bangma $\mathrm{CH}$, et al. Role of genetic testing for inherited prostate cancer risk: Philadelphia Prostate Cancer Consensus Conference 2017. Journal of clinical oncology : official journal of the American Society of Clinical Oncology. 2018;36(4):414-24. https://doi. org/10.1200/JCO.2017.74.1173.

94. Mohler JL, Antonarakis ES, Armstrong AJ, D'Amico AV, Davis BJ, Dorff T et al. Prostate Cancer, Version 2.2019, NCCN Clinical Practice Guidelines in Oncology. J Natl Compr Canc Netw. 2019;17(5):479-505. https://doi.org/10.6004/jnccn.2019.0023. 
95. Tucker MD, Zhu J, Marin D, Gupta RT, Gupta S, Berry WR, et al. Pembrolizumab in men with heavily treated metastatic castrate-resistant prostate cancer. Cancer Med. 2019;8(10):4644-55. https://doi.org/10.1002/cam4.2375.

96. Mota JM, Barnett E, Nauseef JT, Nguyen B, Stopsack KH, Wibmer A, et al. Platinum-based chemotherapy in metastatic prostate cancer With DNA repair gene alterations. JCO Precis Oncol. 2020;4:35566. https://doi.org/10.1200/po.19.00346.

97. Pomerantz MM, Spisak S, Jia L, Cronin AM, Csabai I, Ledet E, et al. The association between germline BRCA2 variants and sensitivity to platinum-based chemotherapy among men with metastatic prostate cancer. Cancer. 2017;123(18):3532-9. https://doi. org/10.1002/cncr.30808.
98. Zafeiriou Z, Bianchini D, Chandler R, Rescigno P, Yuan W, Carreira $\mathrm{S}$, et al. Genomic analysis of three metastatic prostate cancer patients with exceptional responses to carboplatin indicating different types of DNA repair deficiency. Eur Urol. 2019;75(1):184-92. https://doi. org/10.1016/j.eururo.2018.09.048.

99. Hager S, Ackermann CJ, Joerger M, Gillessen S, Omlin A. Antitumour activity of platinum compounds in advanced prostate cancer-a systematic literature review. Ann Oncol. 2016;27(6):975-84. https://doi.org/10.1093/annonc/mdw156.

Publisher's Note Springer Nature remains neutral with regard to jurisdictional claims in published maps and institutional affiliations. 